\title{
OIL SPILL MAP FOR INDIAN SEA REGION BASED ON BHUVAN- GEOGRAPHIC INFORMATION SYSTEM USING SATELLITE IMAGES
}

\author{
Vijaya Kumar L. J ${ }^{1}$, J.K.Kishore ${ }^{2}$, P. Kesava Rao ${ }^{3}$, M,Annadurai ${ }^{4}$, C.B.S. Dutt ${ }^{5}$, K. Hanumantha Rao ${ }^{6}$, S.K. Sasamal ${ }^{7}$, M. Arulraj ${ }^{8}$, \\ A.V.V Prasad ${ }^{9}$, E.V.S. Sita Kumari ${ }^{10}$, S.N. Satyanarayana ${ }^{11}$, H.P. Shenoy ${ }^{12}$ \\ ${ }^{1}$ Master Control Facility, Hassan, Karnataka,INDIA-vijayakumarlj2012@gmail.com \\ ${ }^{2}$ ISRO Satellite Centre, Bangalore, Karnataka, INDIA- jkk@isac.gov.in \\ ${ }^{3}$ IARE Hyderabad, AP, INDIA- pkesavarao@gmail.com \\ ${ }^{4}$ Program Director IRS\&SSS, ISAC, Bangalore, INDIA \\ ${ }^{5}$ Deputy Director, ECS area NRSC, Hyderabad, INDIA -dutt_cbs@nrsc.gov.in \\ ${ }^{6}$ Group Head, Ocean science group, NRSC, Hyderabad, INDIA - rao_kh@nrsc.gov.in \\ ${ }^{7}$ Ocean science group, NRSC, Hyderabad, INDIA -sasmal_sk@nrsc.gov.in \\ ${ }^{8}$ Bhuvan cell, NRSC, Hyderabad, INDIA - arulraj_m@nrsc.gov.in \\ ${ }^{9}$ Group Director DP, NRSC, Hyderabad, INDIA-prasad_avv@nrsc,gov.in \\ ${ }^{10}$ Head MRSDPD, NRSC, Hyderabad, INDIA -sitakumari_evs@nrsc.gov.in \\ ${ }^{11}$ Group Head, CSS, Master Control Facility, Hassan, INDIA \\ ${ }^{12}$ Group Director, SO, Master Control Facility, Hassan, INDIA
}

KEY WORDS: Bhuvan, Oil spill, RISAT-1, SAR images, GIS

\begin{abstract}
:
Oil spills in the ocean are a serious marine disaster that needs regular monitoring for environmental risk assessment and mitigation. Recent use of Polarimetric SAR imagery in near real time oil spill detection systems is associated with attempts towards automatic and unambiguous oil spill detection based on decomposition methods. Such systems integrate remote sensing technology, geo information, communication system, hardware and software systems to provide key information for analysis and decision making.

Geographic information systems (GIS) like BHUVAN can significantly contribute to oil spill management based on Synthetic Aperture Radar (SAR) images. India has long coast line from Gujarat to Bengal and hundreds of ports. The increase in shipping also increases the risk of oil spills in our maritime zone. The availability of RISAT-1 SAR images enhances the scope to monitor oil spills and develop GIS on Bhuvan which can be accessed by all the users, such as ships, coast guard, environmentalists etc., The GIS enables realization of oil spill maps based on integration of the geographical, remote sensing, oil \& gas production/infrastructure data and slick signatures detected by SAR. SAR and GIS technologies can significantly improve the realization of oil spill footprint distribution maps. Preliminary assessment shows that the Bhuvan promises to be an ideal solution to understand spatial, temporal occurrence of oil spills in the marine atlas of India. The oil spill maps on Bhuvan based GIS facility will help the ONGC and Coast Guard organization.
\end{abstract}

\section{INTRODUCTION}

Bhuvan is a GeoPortal of ISRO and it gives India Imaging Capabilities in Multi-sensor, Multi-platform and Multi-temporal geospatial domain. Bhuvan is a gateway to explore and discover virtual earth in $2 \mathrm{D}$ and $3 \mathrm{D}$ space. Bhuvan is of vital for planners, decision makers, social groups, village community and even to common man. Bhuvan is very high potential web based GIS and it's features are utilized by engineers, farmers, forest departments, environmentalists etc., Bhuvan platform can be utilized for providing information about oil spillage in the ocean.

Oil spill pollution has substantial role in damaging marine ecosystem. Oil spill that floats on the top of water, and decreases the amount of intensity of sun light entering into the sea which affects the food chain in the marine ecosystem. Due to pollution of ocean, biological species in the ocean are prone to be destroyed. The entire ocean eco system will be upset. Oil spill is a serious security threat, because ships can come into contact with spilled oil, which can give rise to potential hazards.

In order to avoid accidents and other disasters in the ocean, it is required to map the oil spill incidents in the world map along with its latitude and longitude, so that this information can be used for navigation in the ocean through ship or boat.

Bhuvan Information System can be used for oil spill mapping with Synthetic Aperture Radar (SAR) images. Bhuvan information system to the problem of oil spill mapping includes integration of oil \& gas production/ infrastructure data, remote sensing services, oil spill signatures detection software using SAR and other sensors, geographic location information and GIS (Santilli). Using unsupervised classification of oil spill based on decomposition methods with RISAT-1 Hybrid polarity SAR images, it is possible to detect and separate the oil spill with lookalike. It is further possible to estimate the intensity and physical characteristics of oil spill, pinpoint the location of the oil spill and this information can be used to make oil spill distribution maps. It is proposed that this approach can be applied to oil spill mapping in the Indian ocean, Arabian Ocean and Bay of Bengal.

Recent use of Polarimetric SAR imagery in near real time oil spill detection systems are associated with attempts to fully automatic oil spill detection and identification. Such systems usually combine remote sensing technology, geo information, communication system, hardware and software systems, and provide key information for further analysis and decision 
making. Bhuvan information system can be used for spill related planning and response because it supports integration and preparation of geospatial information on the location, nature and its sensitivities of different resources with rapid access. The developments in the remote sensing and internet technologies also contribute to the improvement in Bhuvan system. As an example, the use of real time multi sensor (visible, TIR, and MIR band images ) satellite information with internet based GIS(Abdallh,2012) (Andrei,2008) system can support the sharing of Bhuvan information ( such as oil spill maps) among users and the public. These systems will allow the integration and display of information from many different sources with different bands of data.

It is advantageous to have integrated system with geo information technology for acquisition, storing and retrieving data and SAR oil spill images, as well as for processing these data into information for environmentalists, researchers and decision makers. Bhuvan can be made, very useful for oil spill mapping, oil spill planning and response. These systems will allow the integration of information from many different sources and these facilities allow the display of this information.

\section{GEOINFORMATION APPROACH FOR OIL SPILL MAP}

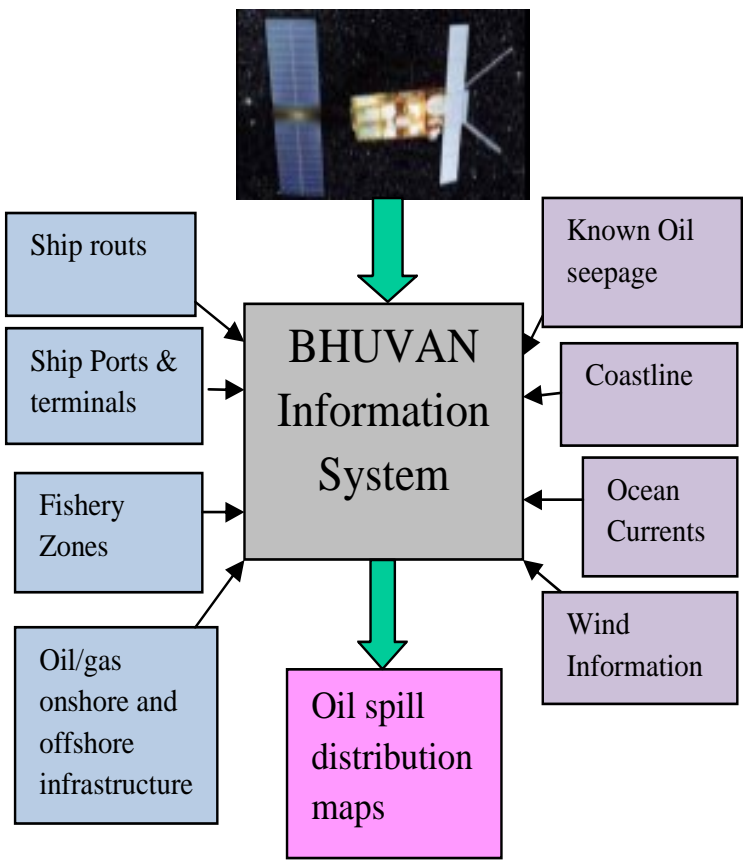

Figure 1. Geo information and Bhuvan information system approach to oil spill mapping based on SAR images

Oil spill signatures on the SAR images in the ocean surface are often classified into three types: natural slicks, look alikes, and man-made oil spills. These signatures in the image can be created by variety of phenomena. The natural slicks are biological surfactants formed from material produced by plankton and fishes. The term "look-alikes" is nothing but, black patches looking like oil slicks, which are produced by phenomena in the upper ocean and low atmosphere and detected in the images as dark patches. It includes low wind areas, rain cells, current shear, algae blooms, internal waves, shoals, grease ice, upwelling, floating vegetation, etc. Refined products and crude oil released into the sea from man-made oil spills. Among several methods cited in literature, decomposition method can be used for detection and discrimination between look-alikes and oil spills. Figure 1 shows the core of the oil spill monitoring system allowing integration of all available data and information and making the final product- oil spill distribution maps for end user/decision makers. The Bhuvan information system approach and use of geographic, remote sensing, and decomposition methods can make an important aid to detection of oil spill and lookalikes.

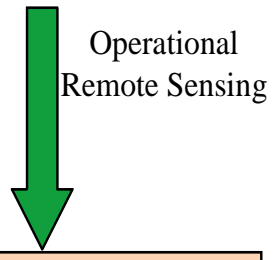

Infra Red line scanner, UV line scanner, Low Light Imaging system , Image intensifier, cameras, Micro Wave Radiometer, cameras, SAR data $e t c$, Weather data, sea state related data

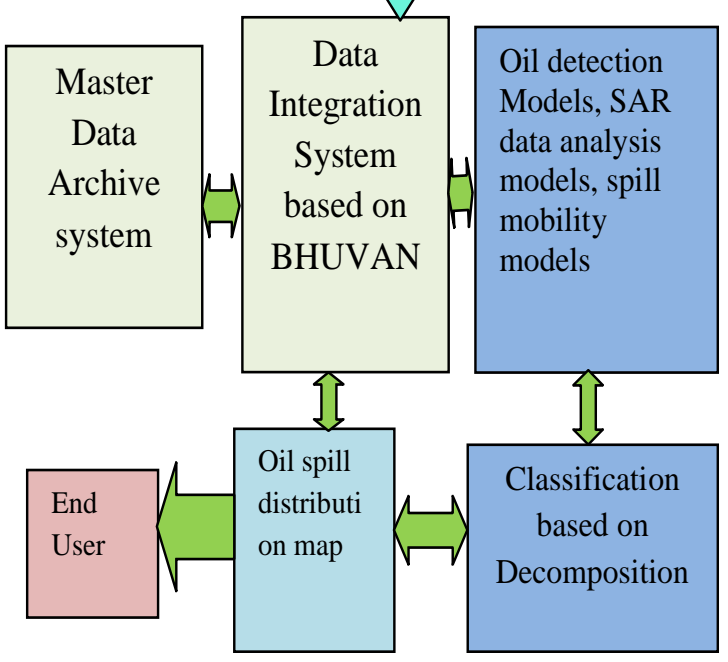

Figure 2. A view of oil spill monitoring system based on BHUVAN Information System

The oil spill monitoring system based on Bhuvan information system is shown in figure 2. The system consists of data integration system based on Bhuvan information system and three subsystems are responsible for acquisition and processing SAR data and other remote sensing data and images; collection in situ measurements and contextual information and archiving of information.

The remote sensed satellite data useful for verification are data on algae blooms provided by the visible/infrared sensors. Wind and rain rates over the ocean can be retrieved from data of microwave scatterometers, altimeters and radiometers. The oil spill drift model can be done using collected remote sensing and in situ data and measurements. 


\section{CASE STUDY OF MUMBAI OIL SPILL MAP ON BHUVAN}

Bhuvan provides an efficient storage, retrieval, visualization and analysis of geographic, industrial and environmental aspects to support oil spill monitoring.

Mumbai is the capital city of the Indian state of Maharashtra, located at the west coast of India. It is the most popular city in India. The port city of greater Mumbai, along west coast of India lies between $18^{\circ} 55^{\prime} \mathrm{N}$ and $19^{\circ} 19^{\prime} \mathrm{N}$ latitude and $72^{\circ} 47^{\prime} \mathrm{E}$ and $73^{\circ} 05^{\prime} \mathrm{E}$ longitude. The total area of Mumbai city is 603.4 $\mathrm{Km}^{2}$. The island city spans $67.79 \mathrm{Km}^{2}$.

An oil spill has been reported off the Mumbai coast after a rupture in the Oil and Natural Gas Corporation (ONGC) main trunk pipeline on 06-Oct-2013. The ruptured trunk oil pipeline carries crude oil from one of India's largest producing oil fields, the Mumbai High fields. The leak was around 5000 litres.

The figure 3 shows MODIS/Terra satellite image taken on 08Oct-2013 which clearly shows oil slicks in the Arabian Sea scattered throughout a 66-mile-long region. The oil spill seen to be generally in the right area corresponds to pipe line problem and their alignment is compatible with the wind blowing from northwest. The location of the accident is at Latitude $=18.756205 \mathrm{~N}$, longitude $=72.968065 \mathrm{E}$. The US Coast Guard classified that as a "medium sized" oil spill. The map of Uran sector in Mumbai is shown in figure 4. The dark patch near Uran shows the oil spillage.

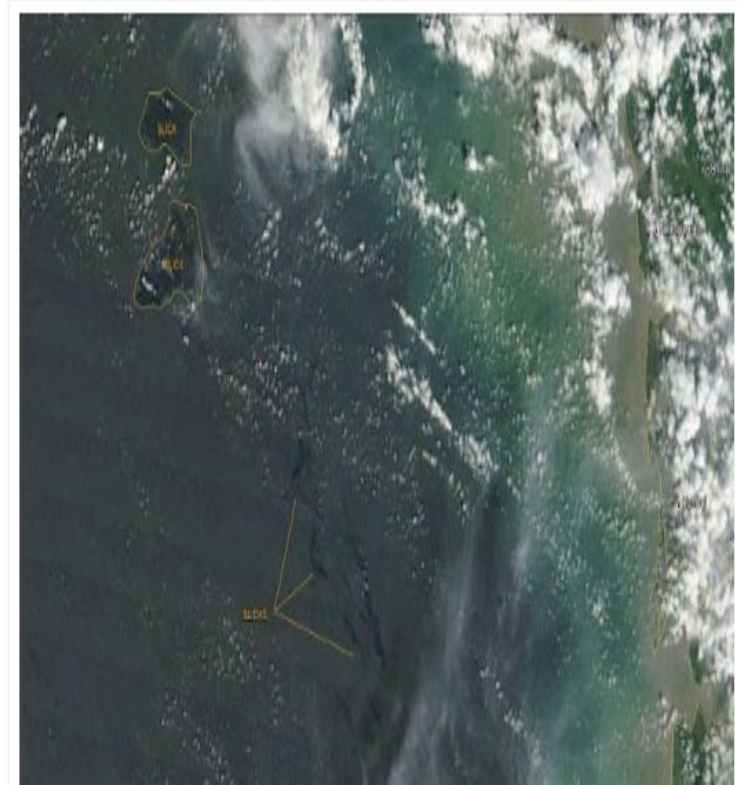

Figure 3. MODIS/Terra satellite image taken October 8,2013, showing apparent oil slicks in the Arabian Sea off the west coast of India near Mumbai. Image courtesy NASA/MODIS.

On 08-Oct-2013 near Dahanu in the western coast of India, the scattered patches of black oil were found with thickness 2-3 $\mathrm{mm}$, width 10-15 meters, with length $2-3 \mathrm{~km}$. The local community confirmed occurrence of such phenomenon every year. The RISAT-1 image was taken over this place with circular transmission and linear reception on $09-$-Oct-2013 at $12: 48: 28$ at latitude $=19.99 \mathrm{~N}$ and longitude $=72.684 \mathrm{E}$. The oil spill was seen at the top left corner of the image in both RV and $\mathrm{RH}$, as seen in figure 5 and 6 . The figure 7 shows the corresponding map. Figures 8, 9, 10, 11 show the m-delta, m- chi, m-psi, m-alpha, decompositions respectively (Lingenahalli, 2013) (Lingenahalli, 2014a,b) for oil spill area. Among these $\mathrm{m}$-delta is providing good signature for oil spill detection.

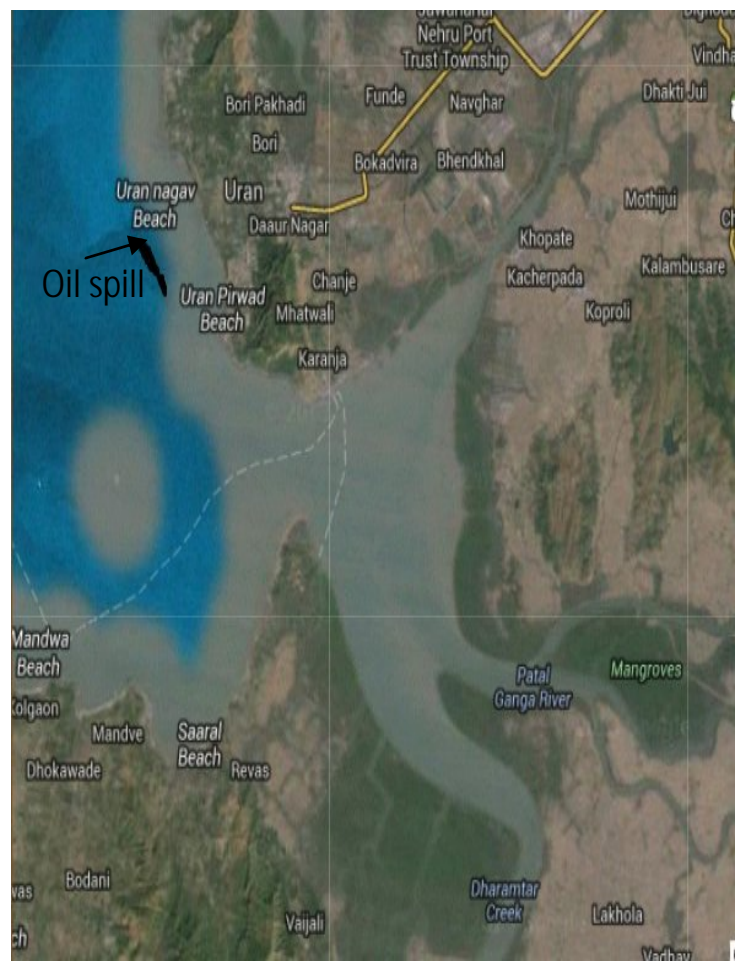

Figure 4. Map of Uran sector in Mumbai, where oil spill occurred is shown in dark patch.

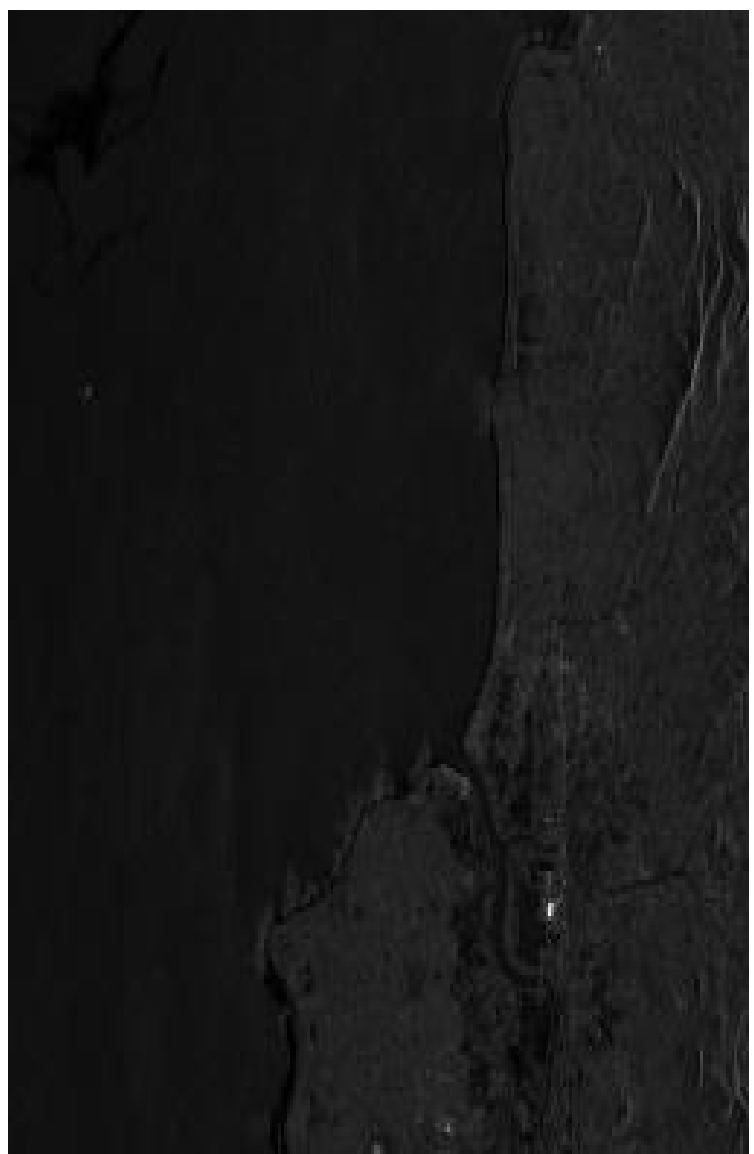

Figure 5. RISAT-1 SAR RV image was taken near Dahanu on 09-Oct-2013. 


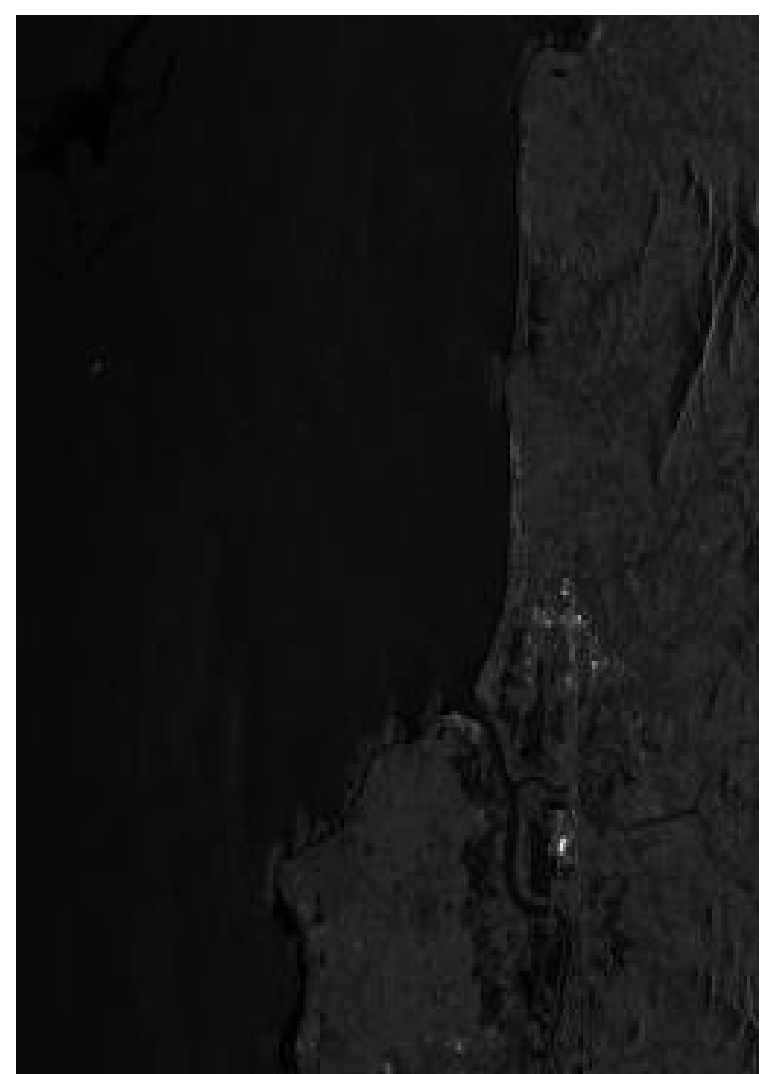

Figure 6. RISAT-1 SAR RH image was taken near Dahanu on 09-Oct-2013.

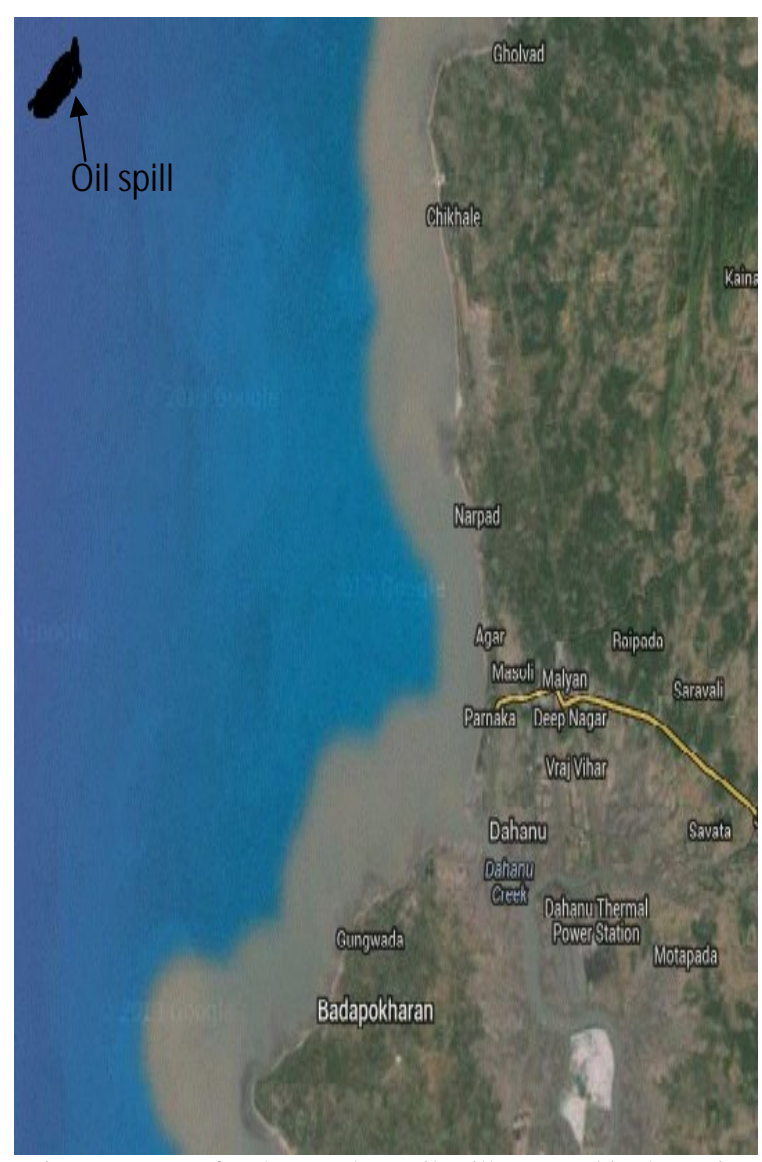

Figure 7. Map of Dahanu, where oil spill occurred is shown in dark patch.

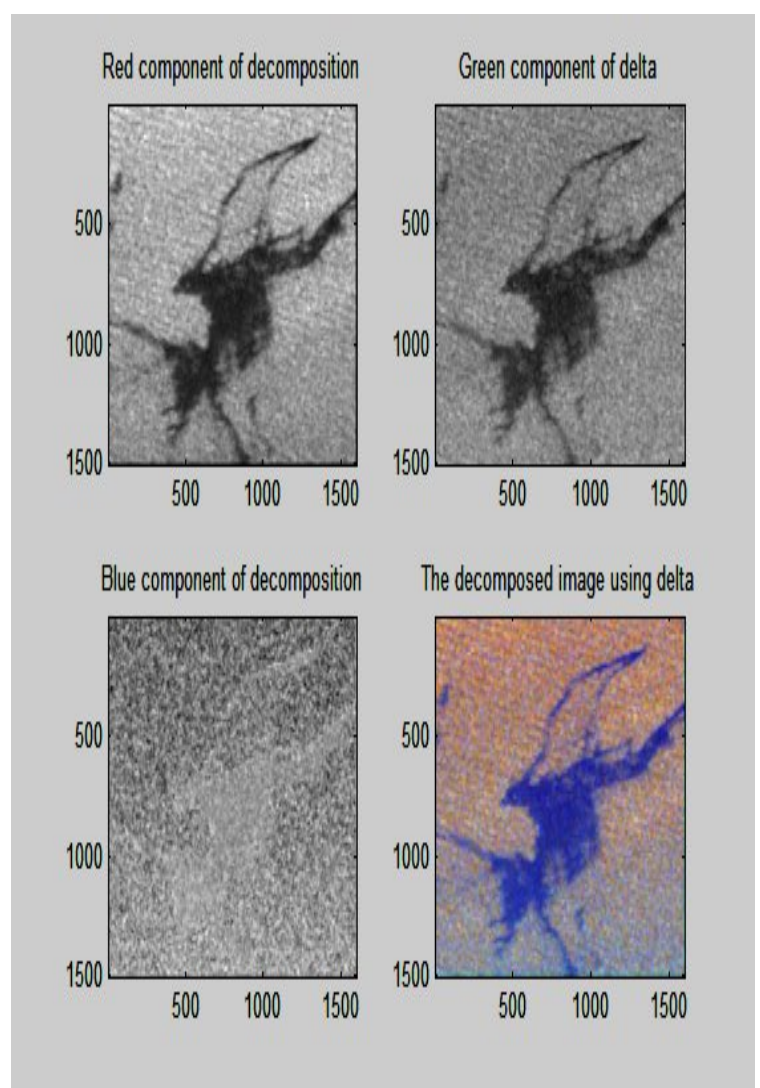

Figure 8. The m-delta decomposed image of Dahanu oil spill area.

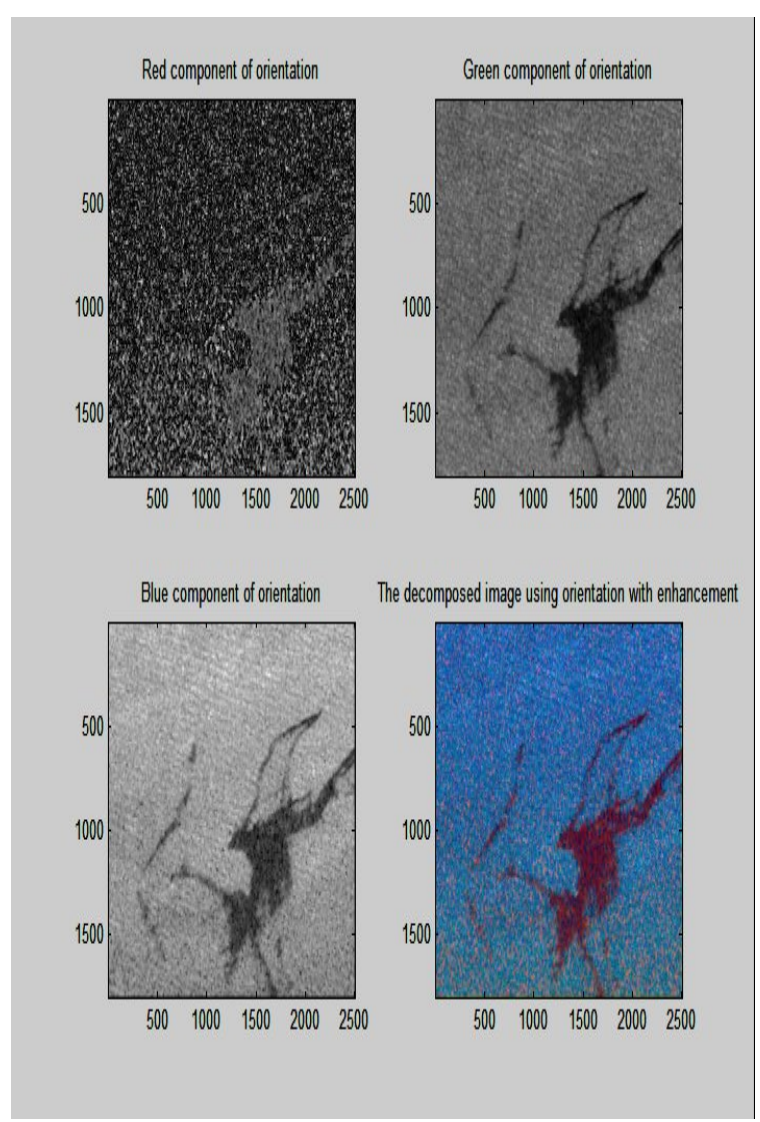

Figure 9. The m-psi decomposed image of Dahanu oil spill area. 


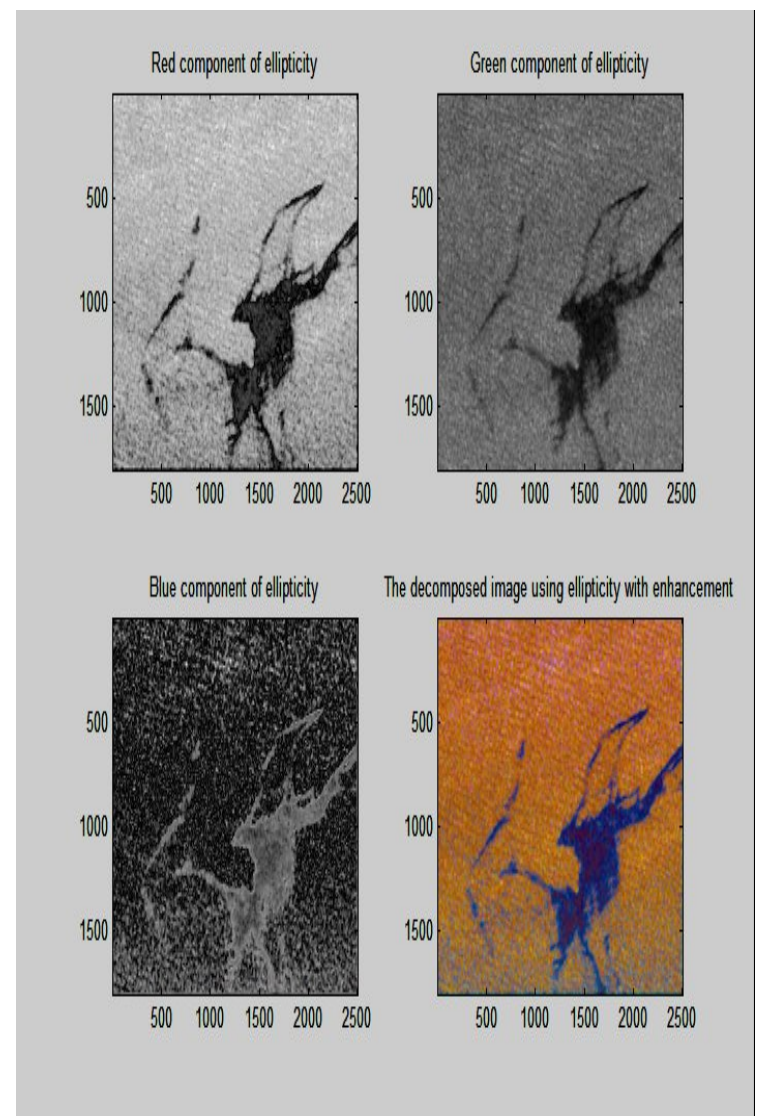

Figure 10. The m-chi decomposed image of Dahanu oil spill area.
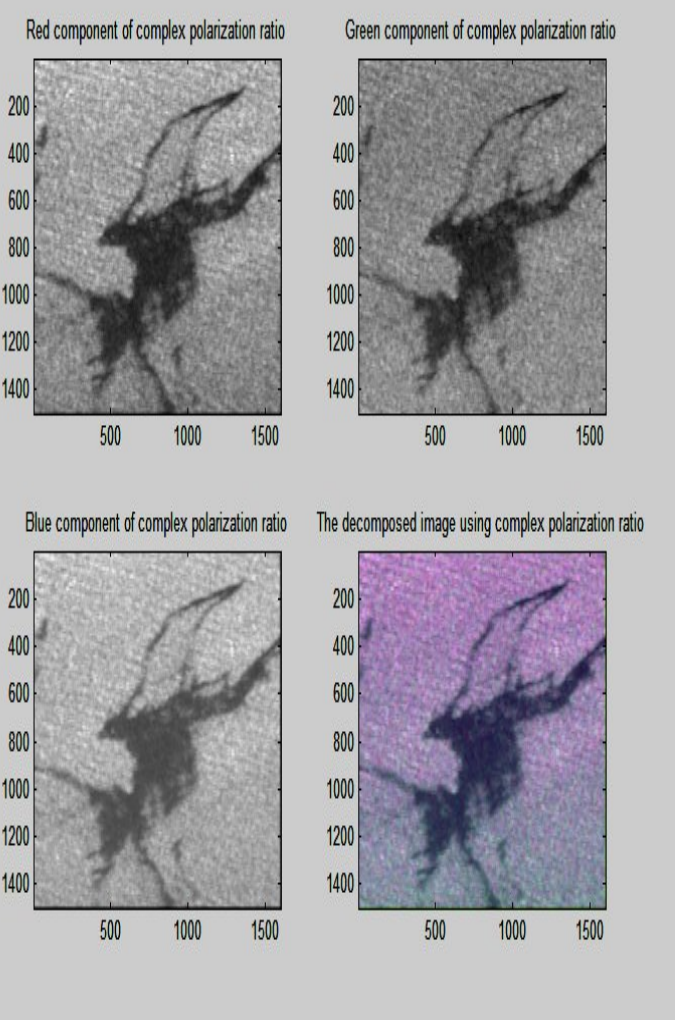

Figure 11. The m-alpha decomposed image of Dahanu oil spill area.

\section{GENERAL PROCEDURE FOR OIL SPILL MAP ON BHUVAN BASED ON OUR SATELLITES}

1. After acquiring image from RISAT-1 in MRS/FRS-1 mode with circular transmission and linear reception, receive the Single Look Complex image of MRS/FRS-1 mode.

2. Besides the decomposition algorithm, apply other slick detection methods on acquired MRS/FRS-1 images.

3. Identify the Oil spill, look alikes using decomposition output and verify with the available remote sensing supplementary data.

4. Tag the oil spill location with longitude and latitude in the image.

5. The longitude and latitude of the step 4 can be used to mark the oil spill location on the map with respect to location. Estimate the physical characteristics of oil spill with remote sensing and associated contextual data.

\section{LIMITATION}

The BHUVAN system mainly depends on availability of satellite services at the time of oil spill at a given location which requires a revisit time of one day or less. On some of the occasions, four to five days outage of satellite service is observed for the particular location due to the orbit configuration. During such occasions imaging opportunities for oil spill surveillance are not adequate. Another limitation is difficult in continuous monitoring of shipping routes and this can be overcome with satellite constellation service.

\section{CONCLUSION}

Geographic information systems (GIS) like BHUVAN has very high scope to significantly contribute to oil spill management based on Polarimetric SAR images and decomposition methods. India has long coast line from Gujarat to Bengal and hundreds of ports. The increase in shipping also increases the risk of oil spills in our maritime zone. The availability of RISAT-1 SAR images enhance the scope to monitor oil spills and develop GIS on Bhuvan which can be accessed by all the users, such as ships, coast guard, environmentalists etc., The oil spill exploration structures and their locations can be identified on BHUVAN along with all the shipping routes. The information from other satellite images can also be added to increase accuracy. The oil spill maps on Bhuvan based GIS will be of use to the organisations such as ONGC and Coast Guard.

\section{ACKNOWLEDGEMENTS}

The authors are thank full to S. Parameswaran, Director, MCF for encouraging research activity at MCF. I thank H.D. Ananda Manager, P. Aravinda Prakash, Manager, for encouraging research activity. The authors wish to thank C. J. Jagadeesha RRSC-B, Hebbar RRSC-B and Kishore Passi of ISAC, for their technical support.

\section{REFERENCES}

Abdallh Eljabri, 2012 Caroline Gallagher, Developing Integrated Remote Sensing and GIS Procedures for Oil Spills Monitoring at Libyan Coast, International Conference on Environment and Bio Science, Singapore,. 
Andrei Yu. Ivanov, Victoria V. Zatyagalova, 2008, A GIS APPROACH TO MAPPING OIL SPILLS IN THE MARINE ENVIRONMENT , International Journal of Remote Sensing Ta 'OF \&Francis. Vol. 29. No. 2|.

Lingenahalli Jayadev Vijaya Kumar, J.K.Kishore, P Kesava Rao,2013,Unsupervised Classification Based on Decomposition of RISAT-1 Images for Oil Spill Detection, IEEE

Lingenahalli Jayadev Vijaya Kumar, J.K.Kishore, P Kesava Rao, 2014a "Marine oil spill detection based on RISAT-1 Hybrid polarity SAR images with decomposition methods and unsupervised classification" Conference (GLAC), Paris, France

Lingenahalli Jayadev Vijaya Kumar, J.K.Kishore, P Kesava Rao 2014b, Decomposition methods for Detection of Oil Spills based on RISAT-1 SAR Images. International Journal of Remote Sensing \& Geoscience volume 3.

Santilli. G, P. Marzialetti, G. Laneve, , A Novel Sinergy Between Remote Sensing and GIS for Oil Spill Detection on Satellite Imagery. 